\title{
Models to Describe the Distribution of Distance Associated with Marriage Migration
}

\author{
Kamlesh Kumar Shukla \\ Indian Institute of Finance, 45A, Knowledge Park-III \\ Greater Noida, NCR/Delhi, India \\ E-mail:kkshukla22@yahoo.com
}

\begin{abstract}
The nature of marriage-migration closely linked to social norms and values along with conjugal laws and behavior among the society. In a society where village endogamy is common, there may not be many marriage-migrations. Marriage migration has no influence on size of the population. It is almost a universal custom for bride to move to bridegroom's home in Indian society. Model is used here based upon distance associated with marriage-migration data of Chandauli district of Uttar Pradesh, India. The suitability of the model is tested with the real data sets and found to be well fitted. The pattern of distance associated with marriage-migration follow the third degree polynomial equation in case of Indian data.
\end{abstract}

Keywords: Marriage-migration, custom, natal home, bridegroom

\section{INTRODUCTION}

Migration is one of the phenomena that people move from one place to the next, which have a several socioeconomic and cultural values. One of the typical types of migration is associated with marriage and has different streams. Marriage migration has no effect on the size and other socio-economic characteristics of the population of the village. The nature of marriage-migration varies from social rules associated with marriages. In a society where 'village endogamy' is common, there may not be many 'marriage-migration'. In rural area, like other parts of India, it is an almost universal custom for bride to move for bridegroom's home. Marriage is always arranged by parents, boys and girls have little say in this matter. Due to increased awareness, better economic conditions and education, some marriage cases are different where it might be arranged by couples themselves. The age of a girl at the time of her marriage becomes very crucial for the parents as it is a custom that she has to leave her natal home permanently and join her in-laws household. This change of residence associated with marriages is usually of permanent in nature and is termed as marriagemigration.

A number of researchers have paid their attention to study the relationship between marriage and migration distance (Hossain 2000, Kosinski \& Prothero 1975, Perry 1969a \& 1969b, Rahaman et al. 2010, Shukla 2002, Sharma 1994, Yadava 1998, Yadav et al. 2002).

The nature of female marriage migration is generally rural to rural and urban to urban for short distances. Few cases are observed from rural to urban and still fewer from urban to rural. This type of migration is balanced in the sense that the 'out-migration', due to marriage from village is almost the same as the 'in-migration' to the village. In such situations the volume and size of migration in the population remains unaffected. It is therefore, the main objective of this paper is to study the pattern of distance associated marriage-migration through a model using real data sets of rural India.

\section{MATERIALS AND METHODS}

The pattern of distance associated with marriagemigration varies from society to society depending upon the customs and social norms. Over the last few decades, a large number of models have been developed to study the distribution of distance associated with marriage migration.

\section{Models}

Sharma (1994) has proposed a probability model to describe the distribution of distance associated with marriage migration in Northern India. According to him the distribution of distance follows an exponential form, that is, the number of marriages in the distance interval $\mathrm{d}_{1}$ to $\mathrm{d}_{2}\left(\mathrm{D}<\mathrm{d}_{1}<\mathrm{d}_{2}\right)$ is given in the following equation.

Where denote the risk parameter associated with the exponential distribution. The reasons of taking this model is:

$$
\left[e^{-\theta(d i-D)}-e^{-\theta(d 2-D)}\right] \pi\left(d 2^{2}-d 1^{2}\right)
$$


(i) up to a certain distance, the distance factor is immaterial and marriage may be arranged without giving due concentration to the distance, and

(ii) after that particular distance, probability of marriages will be decaying function of distance, which may seem to increase in distance involves more expenditure and difficulty on travel.

Yadava et al. (1998) has extended the model proposed by Sharma (1994) where both the parameters and D can be estimated directly, whereas in Sharma's model D has been taken to be known from the observed data. The relationship between marriage and migration distance is given in the following relations.

$$
\mathrm{Y}=\mathrm{a} D^{-b}
$$

Where $\mathrm{Y}$ is the standardized number of marriages at distance ' $D$ '.

This can be re-written as:

$$
\mathrm{Y}=\mathrm{a} e^{-\left(b \log D^{2}\right)}
$$

Which is a log normal function.

To avoid the difficulties of over-under estimation of close in frequencies, both the Pareto and exponential function can be combined together using gravitational concept, which come out to be the Pareto-exponential function. Yadava et al. (2002) tried to show the exponential distribution that provides a better fit to the distribution of marriage-migration associated with distance than that of the Pareto-exponential function (Hossain 2002). Yadava et al. (2002) applied to compare with Pareto-exponential function which was earlier applied by Yadava et al. (1998).

\section{Regression Model}

An effort has been made to apply model to study total marriage-migration associated with distance to the data of Bangladesh (Rahman 2010). A polynomial model is applied (Waerden 1948) and it is given below.

$\mathrm{Y}=\mathrm{f}(\mathrm{X})=\mathrm{a}_{0}+\mathrm{a}_{1} \mathrm{X}+\mathrm{a}_{2} \mathrm{X}^{2}+\mathrm{a}_{3} \mathrm{X}^{3}+\ldots \ldots \ldots+\mathrm{a}_{\mathrm{n}} \mathrm{X}^{\mathrm{n}}$

Where $a_{0}$ is a constant term $a_{i}$ is the coefficients of $X^{i}$ $(\mathrm{i}=1,2,3 \ldots \mathrm{n})$.

An $\mathrm{n}^{\text {th }}$ degree polynomial model is considered in the following form:

$$
Y=\sum_{i=0}^{n} a_{i} x^{i}+U
$$

Where $\mathrm{Y}$ is marriage migration, $\mathrm{X}$ is distance, $\mathrm{a}_{0}, \mathrm{a}_{1} \ldots$ are co-efficients $(i=1,2,3 \ldots . n)$ and $U$ is the stochastic error term of the model. ' $n$ ' has been selected in such a way that the error sum of squares is minimum.

\section{Model Validation}

The validity prediction $\left(\rho_{c v}^{2}\right)$ power is evaluated in order to check the suitability of the model (Stevens 1996).

$$
\rho_{c v}^{2}=1-\frac{(n-1)(n-2)(n+1)}{n(n-k-1)(n-k-2)}\left(1-R^{2}\right)
$$

Where $\mathrm{n}$ is the number of cases, $\mathrm{k}$ is the number of regressors of the model and cross-validated $\mathrm{R}$ is the correlation between observed and predicted values of the dependent variable.

The suitability of the model discussed above has been tested for the real data sets and taken from Shukla (2002). The information related to marriage of boys and girls performed during last three years in household were obtained. Details of the survey data are found in Shukla (2002).

\section{RESULTS}

The estimated parameters and standards error of the fitted polynomial model is presented in Table 1.

Table 1. Parameter estimates and their standard error

\begin{tabular}{|c|c|c|}
\hline \multirow{2}{*}{$\begin{array}{c}\text { Distance interval of } \\
\text { marriage (in } \mathrm{Km} \text {.) }\end{array}$} & \multicolumn{2}{|c|}{ Number of marriage } \\
\hline & Observed & Expected \\
\hline $0-8$ & 20 & 14.08 \\
\hline $8-16$ & 42 & 53.37 \\
\hline $16-24$ & 66 & 70.56 \\
\hline $24-32$ & 88 & 70.90 \\
\hline $32-40$ & 58 & 59.61 \\
\hline $40-48$ & 35 & 41.94 \\
\hline $48-56$ & 24 & 23.13 \\
\hline $56-64$ & 8 & 8.40 \\
\hline $64-72$ & 4 & 3.01 \\
\hline Total & 345 & 345 \\
\hline & $\begin{array}{r}\chi^{2} \\
\text { d.f. }\end{array}$ & $\begin{array}{c}10.58 \\
3\end{array}$ \\
\hline
\end{tabular}

\begin{tabular}{|c|c|c|}
\hline Parameter & Estimate & SE Estimate \\
\hline A & -52.5397 & 22.266 \\
\hline B & 10.2541 & 2.2823 \\
\hline C & -0.2545 & 0.0646 \\
\hline D & 0.0017 & 0.0005 \\
\hline
\end{tabular}

Table 2. Observed and expected distributions of number of marriages associated with distance.

Table 2 shows the distribution of observed and expected number of marriages according to distance interval marriages. It is observed that number of marriages increased with distance of marriages up to $24-32 \mathrm{Km}$. The observed frequencies of marriages are 66 and 88 while the expected values are around 70.56 and 70.90 $\mathrm{Km}$, which is same in both cases. The expected number 
of marriages for the distance intervals $16-24 \mathrm{Km}$. and 24$32 \mathrm{Km}$, has been found to be same.
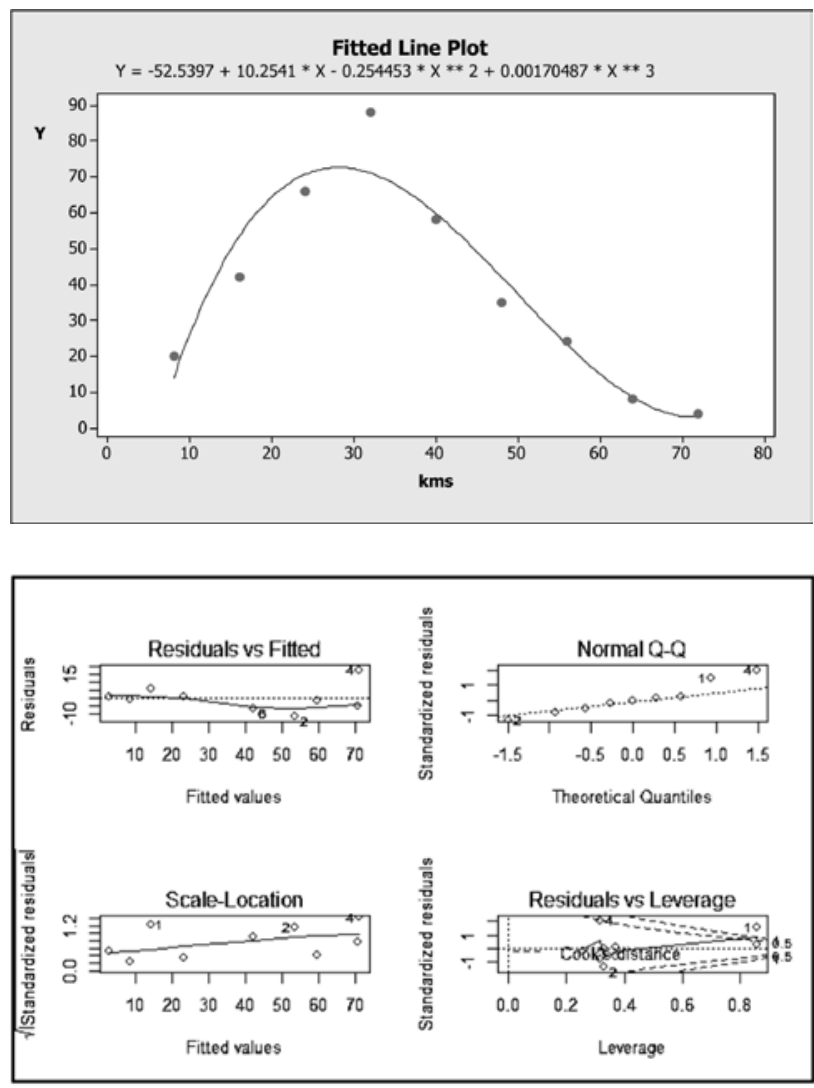

Fig. 1. Distribution of Number of Marriages (Y) associated with distance

Fig. 1 displays that number of marriages increased correspondingly with distance. Beyond distance interval of $(32-40 \mathrm{Km}$.) the trend is declining. This indicates that less number of marriages is performed for distances exceeding $40 \mathrm{Km}$. It may be noted that owing to better ground facilities such as communication and transport coupled with improved economic conditions have altered the average distance for marriage increase from $24 \mathrm{Km}$. (Sharma 1984) to $40 \mathrm{Km}$ in rural Uttar Pradesh, India. However numbers of marriages show a decline trends for cases after $32 \mathrm{Km}$., the situation persists as before.

\section{CONCLUSIONS}

The polynomial model is assumed for marriage migration associated with distance in the Chandauli district of Uttar Pradesh in India. It is found that third degree polynomial model is fitted well to the distribution of distance associated with marriage migration. The suitability of the model is tested with the real data set of marriage migration. The value of $\chi^{2}(10.58)$ is insignificant at 1 percent level significance. Thus it may be concluded that the pattern of marriage migration due to distance follow third degree polynomial model specifically in case of rural India and it may use for the population of same characteristics of rural India and elsewhere.

\section{ACKNOWLEDGEMENTS}

Author is thankful to the anonymous referee for valuable suggestion.

\section{REFERENCES}

Hossain, M.Z. 2000. Some demographic models and their applications with special reference to Bangladesh. $\mathrm{PhD}$ thesis, Department of Statistics, Banaras Hindu University, Varanasi, India.

Kosinski, L.A. and Prothero, R.M. 1975. Marriage and migrartion in ruaral India. In People on the Move: Studies on International, Migration, ed. M.J. Libbee and D.F. Sopher. London: Mthuen and Company.

Perry, P. 1969a. Marriage distance relationship in north Otago 1975-1914. New Zealand's Geographers 25(1): 36-43.

. 1969b. Working class isolation and mobility in rural Dorset 1837-1936: a study of marriage distance. Transactions of the Institute of British Geographers 47: 121-140.

Rahaman, M.M., Akter, S. and Rahaman, A. 2010. Distance associated with marriage migration in a northern and southern region of Bangladesh: an empirical study. Journal of Biosocial Science 42(5): 577-586.

Sharma, L. 1994. A study of the pattern of out-migration from rural areas. Banaras Hindu University, Varanasi, India.

Shukla, K.K. 2002. A study on rural out-migration in northern India. PhD thesis, Departmet of Statistics, Banaras Hindu University, Varanasi, India.

Yadava, K.N.S., Hossain, M.Z. and Islam, S. 1998. Distribution of distance associated with marriage Migration in Rural Areas of Bangladesh. The Bangladesh Journal of Scientific Research 16(2): 201-207.

Yadava, K.N.S., Srivastava, Soni and Islam, S. 2002. Distribution of Distance Associated with Marriage migration. International Journal of Statistical Science 1: 49-54. 